\title{
Endometrial Histopathological Evaluation in Antepartum Hemorrhage for Placental Etiology
}

\author{
Sarbeswar Mandal ${ }^{1}$, Chaitali Karmakar ${ }^{2}$, Masihon Murmu ${ }^{3}$, Nurejjaman ${ }^{4}$, Mahua Mondal $^{5}$, Shermin Siria Begum ${ }^{6}$
}

\begin{abstract}
Aims and objectives: The aims of the study were to investigate and identify the structural changes in endomyometrium in association with placental causes of antepartum hemorrhage (APH).

Background: The microscopic comparative evaluation of endomyometrium in upper and lower segments including placental bed in APH and non-APH.

Type of study: This is a clinical, interventional, prospective, randomized controlled trial (RCT).

Place, duration, and sample size: The study was conducted in the Department of Gynaecology and Obstetrics, IPGMER-SSKM Hospital, Kolkata, West Bengal, India, prior to more than a year.

Methods and materials: After getting ethical approval, sixty-four (64 cases) APH and non-APH patients were selected, randomized, and allowed into two groups for management point of view by cesarean delivery like $\mathrm{Gr}-\mathrm{A}(\mathrm{N}=32)=$ cases $(\mathrm{APH})$; $\mathrm{Gr}-\mathrm{B}(\mathrm{N}=32)=\mathrm{controls}(\mathrm{non}-\mathrm{APH})$.

Four samples from each patient during cesarean delivery of randomly selected cases and controls each from upper lower, anterior, and posterior with one must from placental bed were taken and studied microscopically.

The results of microscopic features revealed that there were hemorrhage, an unusual, abnormal vascular structure, absent deciduas changes, direct contact between placenta and myometrium with higher trophoblast infiltration into deciduas, myometrium, and vessels with decreased villous fibrin deposition.

Conclusion: The decidua has a major role to play in negotiating "the treaty of compromise" ultimately signed between fetal and maternal tissues if such a treaty is not signed or broken, defective placentation (imperfect fibrinoid-Nitabuch layer) and its consequence must follow. Keywords: APH, Decreased fibrin deposition, Endomyometrial biopsy, Hemorrhage, Less physiological changes, Trophoblast invasion. Journal of South Asian Federation of Obstetrics and Gynaecology (2021): 10.5005/jp-journals-10006-1954
\end{abstract}

\section{INTRODUCTION}

In spite of advances in medical sciences, still the leading cause of maternal and perinatal mortality and morbidity is obstetric hemorrhage $(>30 \%)$ of which antepartum hemorrhage (APH) (approx. $5 \%$ of hospital attendants) kills mother about 10\%. The APH (placenta previa (PP) - 25\%, abruption placenta-40\%, ill health$60 \%$ ) causes blood loss more than $2.5 \mathrm{~L}$ (blood transfusion required $\geq 5$ units), presents with serious complicated, exsanguinated, most morbid hemorrhagic shock state (6-7\%), alarming hemorrhage (33.5\%), admitted good (38\%), admitted bad (60\%), causes maternal mortality $6-7 \%$, morbidity $40 \%$, hemorrhage death $(0.5 \%)$, and preterm (27\%). ${ }^{1-3}$

Till today the exact causes of APH remains obscure and unknown though there are some proposal in $\mathrm{APH}$ where there are not only degeneration and necrosis due to vascular origin specially spiral arteries at basal plate with vascular disruption and hematoma formation but also such type of pathogenesis in the chorionic villi and its vessels might impose serious side effects on the developing fetus. ${ }^{4,5}$

The PP is one of the important causes of third trimester bleeding and consequently leads to serious maternal, fetal, and neonatal morbidity and mortality. ${ }^{6}$ In spite of many controversial etiological agents proposed from time to time, advanced maternal age (over 35 years), multiparity, multiple pregnancy, prior cesarean delivery, smoking, infertility treatment, and male fetus are some risk factors of $\mathrm{PP}^{7-9}$ damage to the endometrium, and myometrium has been implicated with conflicting results in the etiopathogenesis of PP. ${ }^{10,11}$
${ }^{1-6}$ Department of Obstetrics and Gynaecology, IPGMER-SSKM (PG) Hospital, Kolkata, West Bengal, India

Corresponding Author: Sarbeswar Mandal, Department of Obstetrics and Gynaecology, IPGMER-SSKM (PG) Hospital, Kolkata, West Bengal, India, Phone: +91 9474800252, e-mail: drsarbeswarmandal@gmail.com How to cite this article: Mandal S, Karmakar C, Murmu M, et al. Endometrial Histopathological Evaluation in Antepartum Hemorrhage for Placental Etiology. J South Asian Feder Obst Gynae 2021;13(5): 327-332.

Source of support: Nil

Conflict of interest: None

It has been shown that neonatal mortality rate in pregnancies complicated by PP increased threefold and fetal anomalies increased 2.5 -fold in comparison with normally positioned placentas. ${ }^{12}$

The PP (1 in 300 deliveries) is practically required cesarean section because the poorly contractile nature of the lower uterine segment, with uncontrollable postpartum bleeding, ${ }^{13}$ is an important cause of maternal and perinatal (preterm birth) mortality and morbidity.

There are histological evidences of inflammation and infection which may contribute to causal pathways, ${ }^{14}$ and vascular malformations in association with placental may be the result of trophoblastic invasion and could be the site of vessels rupture. ${ }^{15} \mathrm{FOX}$ reported that decidua formation is commonly defective in lower

() The Author(s). 2021 Open Access This article is distributed under the terms of the Creative Commons Attribution 4.0 International License (https://creativecommons. org/licenses/by-nc/4.0/), which permits unrestricted use, distribution, and non-commercial reproduction in any medium, provided you give appropriate credit to the original author(s) and the source, provide a link to the Creative Commons license, and indicate if changes were made. The Creative Commons Public Domain Dedication waiver (http://creativecommons.org/publicdomain/zero/1.0/) applies to the data made available in this article, unless otherwise stated. 
segment in previous scar, ${ }^{16}$ placenta adhered (50\% cases) myofibril fibers detected microscopically ${ }^{17}$ and lastly PP is associated with significantly highly trophoblastic infiltration and physiological changes in myometrial spiral arteries.

Surprisingly, it was observed that "there is no eclampsia in PP cases and, on the contrary, in severe toxemia of the late pregnancy, low implantation of the placenta is met only exceptionally." This inverse relation is thought to be due to improved uteroplacental blood supply and probability for placenta implanted in the lower uterine segment draws its primary blood supply from the uterine vessels in contrast to ovarian vessels that perfuse the placenta implanted in the fundus of uterus. ${ }^{18,19}$

As many previously mentioned studies demonstrated that placental bed biopsy evaluated changes in normal and abnormal pregnancies and has been proved to be quite safe; ${ }^{20}$ hence, the present study was designed to study the placental bed biopsy in cases of PP and normally located placenta in order to evaluate and compare the extent of trophoblastic invasion and physiological changes in decidua and myometrium. So this study directed to find out what type of histopathological changes occurs in uterus which ultimately responsible for placental causes of $\mathrm{APH}$.

\section{Methods and Materials}

After getting ethics approval, patients with APH were selected, randomized, and allowed into two groups as per selection and exclusion criteria with CONSORT FLOWCHART: Gr-A $(N=32)=$ cases$\mathrm{APH}$ and $\mathrm{Gr}-\mathrm{B}(\mathrm{N}=32)=$ non-APH.

\section{Case Selection}

Setting: Academic, Research.

Place of study: Department of Gynaecology and Obstetrics, IPGMERSSKM Hospital, West Bengal, India.

Duration: 1 year (from February 19, 2015 to February 18, 2016)

Sampling method: Prospective randomized controlled study, Clinical trial, Comparative study.

Sample size calculation: The total of 64 patients were selected with an allocation into $\mathrm{Gr}-\mathrm{A}(n-32)$ cases and $\mathrm{Gr}-\mathrm{B}(n-32)$ (controls).

Allocation and follow-up: Allocation was done into Gr-A (Cases) and Gr-B (Controls) with equal numbers and intervention done accordingly and follow-up as per standard guidelines.

\section{Case Selection [Eligibility Criteria (Inclusion Criteria)]}

All cases (both nullipara and multipara) (total-64) of APH and non-APH with normally located placenta were included for the study.

\section{Exclusion Criteria}

The following are the exclusion criteria:

- Coagulation and bleeding disorders, anticoagulant therapy, $\mathrm{Hb}$ $<10.5 \%$.

- Immunocompromised and connective tissues disorders.

- Associated medical and surgical comorbidities.

- APH of unknown etiology.

- Premature rupture of membrane.

- Unclean examination was excluded from the study.

\section{Data Collection Procedure}

Allocation was done into Gr-A (cases) and Gr-B (controls), where numbers were generated by computerized random number generator. For this the envelopes of same size, shape and weight were selected over it the name and other details of the participants were recorded on then and were opened sequentially. Those envelops contain carbon papers which are essential for audit trial. The patients' profiles were entered on the registry.

\section{Data Analysis}

The outcomes of individual groups analyzed are as follows:

- Primary outcomes (organ damage/failure, blood loss, transfusion),

- Secondary outcomes (operation time, mobilization time, oral intake time, analgesic, pain relieved, and satisfaction),

- secondary outcomes (wound complications, hospital stay, costs and readmission), and

- Newborn outcomes tabulated and statistically significantly calculated by GraphPad Software in Tables 1 to 3.

Ethical consideration and approval: The study was duly applied to and approved by the Institutional Ethics Committee, and the certificate was enclosed.

Any scoring system: It is associated with impairment of healthrelated quality of life (HRQOL).

Surgical procedure: During cesarean operation surgically removal of four samples containing endomyometrium each from upper segment (anterior and posterior) lower (anterior and posterior with one must from placental bed) from inner aspect of uterine walls were taken from selected cases and controls and studied microscopically.

\section{Methods and Techniques}

Placental bed biopsy was taken during cesarean section in 64 pregnant women as per the selection and recommendation of inclusion and exclusion criteria. They were divided into two groups. The study group was comprised of 32 (cases) pregnant women who had undergone cesarean section due to PP and the control group was consisted of 32 (controls) non-APH pregnant women who were matched for age and parity with the study group and had normally located placenta and patients with APH.

Informed consent was taken and placental bed biopsy was carried out under direct visualization.

During the surgery (LSCS) of selected cases and controls with curved scissors or scalpel a disc or circular $(1.5 \mathrm{~cm}$ in diameter) shaped surgically removed sample contained basal deciduas and underlying myometrium of uterine walls were removed from upper, lower, anterior, and posterior with one must from placental bed were taken and studied microscopically.

The resulting defect was closed with absorbable sutures with proper hemostasis. There are no alteration and or modification in cesarean procedure.

The biopsy was mounted in buffered formalin. After tissue processing, the 3-um-thin serial sections were cut and stained with hematoxylin $(\mathrm{H})$ and eosin $(\mathrm{E})$ and were subjected to histopathological examination.

All placentas were delivered, the umbilical cord was clamped and cut, and all the details were duly recorded. 
The histopathological changes were recorded and analyzed in detail with respect to the following parameters:

- Representative placental bed biopsy-presence of trophoblastic giant cells and/or physiological changes of the vessels.

- Nonrepresentative-absence of trophoblasts or physiological changes in the biopsy despite the presence of decidua and/or myometrium.

- Assessing crude quantitation by counting a number of extra villous trophoblasts (intermediate trophoblasts) in the decidua and myometrium separately.

Histopathological consideration criterion is described in the form of the presence of dilated spiral arterioles with a replacement of their musculoelastic layer with hyaline eosinophilic homogenous material, infiltration of muscular layer of vessel wall by extra villous trophoblasts, replacement of lining endothelial cells of intimae by marked pyknotic bizarre hyperchromatic nuclei, inflammatory cell infiltrate in vessel wall, decidua and myometrium, inadequate/absence of physiological changes from myometrium in spite of the presence of extravillous giant cells, the presence of infarction, intimal hyperplasia with or without thrombus, and lastly and most importantly hemorrhage.

\section{Results}

Maternal characteristics are described and compared in Table 1 of cases (APH) and controls (non-APH) with a number of pregnancy complications who had been age and gestational age matched. Maternal parameters, fetal parameters, and placental parameters were recorded in the information form and then tabulated, and statistical significance was calculated by using GraphPad Software.

There are differences in the mean of the characters of the patients in PP and study group with a statistical significance in relation to age (years) $(p=0.0430)$, POG (weeks) $(p=0.0001)$, gravida/parity $(p=0.0446)$, placenta weight $(p=0.0001)$, umbilical cord ( $p=0.0001)$, and risk factors (abortions, history of (H/o) lower segment caesarean section (LSCS), sepsis, smoking, infertility, and multiple pregnancy $-p<0.0001$ ), especially that the average placental weight increment to controls group is statistically significant with the umbilical cord diameter in PP group was reduced statistically significant compared controls.
In Table 2, the results of individual groups ( $\mathrm{Gr}-\mathrm{A}$ and $\mathrm{Gr}-\mathrm{B}$ ) by the endomyometrial. Histopathological evaluation including placental bed biopsy assessed, analyzed, and represented with the statistical significance accordingly showed the following mentioning points:

The results of individual groups (Gr-A and Gr-B) of endomyometrial histopathological examination reports were assessed, analyzed and revealed that in cases ( $\mathrm{Gr}-\mathrm{A}$ ) there were statistical significant of the representativeness of sample ( $p=0.0001)$, the physiological changes $(p=0.0011)$ the hemorrhage $(p<0.0001)$, the vessels with trophoblastic giant cell ( $p=0.0018$ ), the myometrium directly contact between placenta and myometrium $(p=0.0107)$, the deciduas mostly placental bed extra villous trophoblast ( $p<0.0001)$, less fibrin deposit $(p<0.0001)$ and the inflammatory cell infiltrate $(p=0.0219)$.

The newborn outcomes in Table 3 in both the cases and the controls with their statistical significances revealed that the incision to delivery $(p<0.0001)$, cried at birth $(p<0.0001)$, preterm ( $p=0.0001)$, intrauterine growth restriction (IUGR) $(p=0.0001)$, meconium staining $(p<0.0001)$, birth trauma $(p=0.0157)$, E.N.C $(p<0.0001)$, the APGAR score $(p<0.0023-p<0.0003)$, baby weight $(p<0.0047, p<0.0051, p<0.0234, p<0.0001)$, the neonatal intensive care unit (NICU) admission ( $p=0.0413)$, and death ( $p=0.1132$ ) having male-to-female ratio of newborns without any significance.

\section{Discussion}

Till date, the etiology of PP remains controversial and most of the studies propose a multifactorial origin. Some previous studies ${ }^{21}$ did not find statistically significant differences in the incidences of risk factors predisposing. Some study on placental bed biopsy ${ }^{22-25}$ was described that the representative in $84 \%$ samples of the study group and (70\%) samples of the control group, only $44 \%$ cases giant cells, trophoblastic invasion in $100 \%$ of decidua spiral arteries and $76 \%$ of myometrial arteries, fibrinoid necrosis, acute inflammatory cell infiltrate, extra villous trophoblast (uninuclear or binuclear) with unusual uteroplacental vasculature and lacked physiological changes with cluster of intercommunicating vascular channels showed subintimal basophilic deposition with narrowing of lumen. Some investigators hypothesized that ${ }^{26-28}$ there were low incidence of pregnancy induced hypertension $(\mathrm{PIH})$ in PP attributed

Table 1: Maternal characteristics

\begin{tabular}{lccc}
\hline Parameters & $\begin{array}{c}\text { Study group }(n=32) \\
\text { (seen/not) }\end{array}$ & $\begin{array}{c}\text { Control group }(n=32) \\
\text { (seen/not) }\end{array}$ & $\begin{array}{c}\text { FET/UTT } p \text { value } \\
\text { Two-tailed } p \text { value }\end{array}$ \\
\hline Age (years) (average) & $29(22 / 10)$ & $24(13 / 19)$ & $p=0.0437$ \\
Gravida/parity & $4.5 / 2.5(21 / 11)$ & $2 / 1(12 / 20)$ & $p=0.0446$ \\
POG (weeks) & $36.5(22 / 10)$ & $3(1)(3 / 29)$ & $p=0.0001$ \\
Placenta weight & Less-30/2 & $0 / 32$ & $p=0.0001$ \\
UC diameter & Less-28/4 & $2 / 30$ & $p=0.0001$ \\
H/o abortions & $25 / 07$ & $08 / 24$ & $p<0.0001$ \\
H/o Cesarean section & $27 / 05$ & $08 / 24$ & $p<0.0001$ \\
H/o sepsis & $28 / 04$ & $07 / 25$ & $p<0.0001$ \\
H/o smoking & $19 / 13$ & $08 / 24$ & $p=0.0107$ \\
H/o infertility & $29 / 03$ & $04 / 28$ & $p<0.0001$ \\
H/o twin and others & $26 / 06$ & $04 / 28$ & $p<0.0001$ \\
\hline "Unpared t-test (UT), ${ }^{*}$ Fishers
\end{tabular}

"Unpaired $t$-test (UTT), ${ }^{*}$ Fisher's exact test (FET), ${ }^{*}$ Mean, ${ }^{*}$ SD, ${ }^{*}$ SEM 
Table 2: Endomyometrial histopathology including placental bed biopsy study report

\begin{tabular}{|c|c|c|c|}
\hline Parameters/indicators & $\begin{array}{c}\text { Study cases }(n=32) \\
\text { (seen } / \text { not })\end{array}$ & $\begin{array}{c}\text { Controls }(n=32) \\
(\text { seen/not) }\end{array}$ & $\begin{array}{l}\text { FET/UTT } p \text { value } \\
\text { Two-tailed } p \text { value }\end{array}$ \\
\hline Representative & $26 / 6$ & $10 / 22$ & $p=0.0001$ \\
\hline $\begin{array}{l}\text { Physiological changes-decidua/ } \\
\text { myometrium/decidua-myometrium }\end{array}$ & $15 / 17$ & $28 / 4$ & $p=0.0011$ \\
\hline Hemorrhage & $32 / 00$ & $00 / 32$ & $p<0.0001$ \\
\hline $\begin{array}{l}\text { Vessels (spiral artery changes-60\%) } \\
{ }^{*} \text { Cells infiltration in decidua }(71 \%) \\
{ }^{*} \text { Cell infiltration in myometrium (33\%) } \\
{ }^{*} \text { Cell infiltration }(89 \%)\end{array}$ & $\begin{array}{l}26 / 06 \\
25 / 07 \\
27 / 05 \\
28 / 04\end{array}$ & $\begin{array}{l}13 / 19 \\
08 / 24 \\
08 / 24 \\
07 / 25\end{array}$ & $\begin{array}{l}p=0.0018 \\
p<0.0001 \\
p<0.000 \\
p<0.0001\end{array}$ \\
\hline $\begin{array}{l}\text { Myometrium } \\
{ }^{*} \text { Cellular infiltration }\end{array}$ & $19 / 13$ & $08 / 24$ & $p=0.0107$ \\
\hline $\begin{array}{l}\text { Decidua } \\
{ }^{*} \text { Cellular infiltration } \\
{ }^{*} \text { Special giant cells } \\
{ }^{*} \text { No decidual and chorionic villi }\end{array}$ & $03 / 29$ & $28 / 04$ & $p<0.0001$ \\
\hline $\begin{array}{l}\text { Cells (trophoblast and giant cells) } \\
\text { (increased in case) } \\
\text { Decidua } \\
\text { Myometrium } \\
\text { Spiral artery }\end{array}$ & $\begin{array}{l}13 / 19 \\
13 / 19 \\
26 / 06\end{array}$ & $\begin{array}{l}04 / 28 \\
04 / 28 \\
04 / 28\end{array}$ & $\begin{array}{l}p=0.0219 \\
p=0.0219 \\
p<0.0001\end{array}$ \\
\hline *Fibrin deposit & $06 / 26$ & $07 / 25$ & $p<0.0001$ \\
\hline *Inflammatory cell infiltrate & $19 / 13$ & $03 / 29$ & $p=0.0219$ \\
\hline
\end{tabular}

Table 3: Newborn outcomes

\begin{tabular}{lccc}
\hline Indicators & $\begin{array}{c}\text { Gr-A-cases } \\
(32)\end{array}$ & $\begin{array}{c}\text { Gr-B-controls } \\
(32)\end{array}$ & $\begin{array}{c}\text { FET/UTT } p \text { value } \\
\text { Two-tailed } p \text { value }\end{array}$ \\
\hline $\begin{array}{l}\text { Incision to } \\
\text { delivery }\end{array}$ & $10,2,28$ & $15,5,71$ & $p<0.0001$ \\
Cried at birth & $27 / 5$ & $15 / 17$ & $p<0.0033$ \\
Preterm & $66 \%(21 / 11)$ & $12 \%(4 / 28)$ & $p<0.0001$ \\
IUGR & $25 / 7$ & $6 / 26$ & $p<0.0001$ \\
Meconium & $6 / 26$ & $15 / 17$ & $p<0.0319$ \\
staining & & & \\
Birth trauma & $1 / 31$ & $9 / 23$ & $p=0.0127$ \\
E.N.C. & $3 / 29$ & $17 / 15$ & $p<0.0003$ \\
APGAR score & & & \\
$7-10$ & $24 / 8$ & $11 / 21$ & $p<0.0023$ \\
$4-6$ & $6 / 26$ & $21 / 11$ & $p<0.0003$ \\
Baby weight & $2.12 \pm 0.545 \mathrm{~kg}$ & $2.6 \pm 0.544 \mathrm{~kg}$ & \\
$\quad<1.5 \mathrm{~kg}$ & $7 / 25$ & $19 / 13$ & $p<0.0047$ \\
$1.5-2 \mathrm{~kg}$ & $8 / 24$ & $20 / 12$ & $p<0.0051$ \\
$2-2.5 \mathrm{~kg}$ & $12 / 20$ & $22 / 10$ & $p<0.0234$ \\
$>2.5 \mathrm{~kg}$ & $9 / 23$ & $25 / 07$ & $p<0.0001$ \\
NICU admission & $4 / 28$ & $12 / 20$ & $p=0.0413$ \\
Death & $0 / 32$ & $2 / 30$ & $p=0.1132$ \\
\hline
\end{tabular}

"Unpaired $t$-test (UTT), ${ }^{*}$ Fisher's exact test (FET), ${ }^{*}$ Mean, ${ }^{*} \mathrm{SD},{ }^{*} \mathrm{SEM}$

to increase in blood supply and oxygen lower uterine segment by altering trophoblastic giant cells. In spite of this changes there were low birth weight and growth retarded fetuses.

In the present study, the microscopic reports of cases (Gr-A) of $\mathrm{APH}$ demonstrated that there were significant representativeness of samples, lack of physiological changes (fibrinoid changes/ hyalinization of vessel wall followed by intimal hyperplasia, and myometrial blood vessels), the absolute and the relative volume of blood vessels with trophoblastic giant cell in myometrial, uteroplacental vasculature and myometrial spiral arteries increased and deciduas exhibited extra villous trophoblast and lower interstitial trophoblast. There were direct contact between placenta and myometrium with the hemorrhage into deciduas and myometrium was a significant finding in all cases of placenta APH with increase in the mean number of trophoblastic giant cells in deciduas and myometrial blood vessels. In addition to the above mention microscopic finding there were statistically significant acute inflammatory cell infiltrate in myometrium and blood vessels wall in the previa group with reduction of absolute and the relative volume of fibrin deposit with fibrinoid necrosis.

\section{Conclusion}

The decidua has a major role to play in negotiating "the treaty of compromise" ultimately signed between feta and maternal tissues if such a treaty is not signed or broken, defective placentation (imperfect fibrinoid-Nitabuch layer) and its consequence must follow. So this study directed to find out what types of histopathological changes occur in uterus which ultimately are responsible for placental causes of $\mathrm{APH}$, showed statistically significant hemorrhage with vascular abnormalities, myometrial and decidua cellular infiltration especially giant cells and inflammatory cells in nature the only thing deposited fibrin reduced. The genetically predispose, immunomediated, reduced fibrin deposition along with vascular and antithrombotic changes leads to abnormal decidua formation; imperfect Nitabuch layer may be an etiological aspect for APH.

\section{Significance-What's NeW}

As this minimal interventional procedure was carried out under direct visualization safely and effectively without any intraand postoperative complication, this method had not been 
compromised the reproductive events and future fertility, except the formation of minor scar on the maternal womb; there was no adverse effect on pregnancy, and this type of minor intervention without any early and late complications is helpful for such type of research purpose though there are many alternative methods like magnetic resonance imaging (MRI), ultrasonography (USG) color Doppler study, and, in recent times, stereotactic study, but this is better because it produced a better result without adverse effects. It is a new technique carried out intraoperative period with ideal representatives of sample collection to find out any abnormalities or defects in uterus/endomyometrium.

\section{Acknowledgments}

Authors would like to thank all the patients recruited in the study and all the members of the Department of Obstetrics and Gynaecology and thankful to Institutional Ethics Committee, IPGMER-SSKMH, Kolkata, India.

Contribution of Authorship: All authors contributed to the design, literature reviewed, and writing of the article.

Ethics Approval: This is duly approved by the Institutional Ethics Committee.

Trial Registration Number: Not required.

Orcid Registry No: *ORCID iD=http://orcid.org/0000-0002-6255 -7096. *ORCID iD=http://orcid.org/0000-0002-6122-3051.

\section{References}

1. Penny G, Kernaghan D, Adamson L. Scottis confidential audit service maternal morbidity. Second Annual Report; 2005.

2. Department of Reproductive Health and Research, WHO maternal morbidity in 2000 estimates, developed by WHO, UNICEF, UNFPA. Geneva. WHIO; 2004.

3. Waterstone $\mathrm{M}$, Bewley $\mathrm{S}, \mathrm{Wolfe} \mathrm{C}$. Incidence and predictors of severe obstetric morbidity: case-control study. BMJ 2001;322(7294): 1089-1093; discussion 1093-1094. DOI: 10.1136/bmj.322.7294.1089.

4. Heidari Z, Mahmoudzadeh-Sagheb H, Zakeri Z, et al. Stereological changes of human placenta in systemic lupus erythematosus compared with healthy controls. ZJRMS 2013;15(7):50-54. Available from: https://www.sid.ir/en/journal/ViewPaper.aspx?id=336

5. Zhang L, Wang Y, Liao AH. Quantitative abnormalities of fetal trophoblast cells in maternal circulation in preeclampsia. Prenat Diagn 2008;28(12):1160-1166. DOI: 10.1002/pd.2135.

6. Mc Shane PM, HeyI PS, Epstein MF. Maternal and peri-natal morbidity resulting from placenta previa. Obstet Gynecol 1985;65(2):176-182. PMID: 4038547.

7. Naeye RL. Placenta previa, predisposing factors and effect on the fetus and surviving infants. Obstet Gynecol 1978;52(5):521-525. PMID: 724168.

8. Cunningham FG, Leveno KJ, Bloom SL, Spong YC, Dashe SJ,Hoffmann LB,KCasey MB, Sheffield SJ, Editors. Obstetrical hemorrhage. Text book of Williams obstetrics, 25TH Edition. New York: McGrowHill;2018. p.755-802(Sec-11 \& Chap-41).

9. Nyango DD, Mutihir JT, Kigbu JH. Risk factors for placenta praevia in Jos, north central Nigeria. Niger J Med 2010;19(1):46-49. DOI: 10.4314/ njm.v19i1.52479.
10. Clark SL, Koonings PP, Phelan JP. Placenta previa/accreta and prior cesarean section. Obstet Gynecol 1985;66(1):89-92. PMID: 4011075.

11. Naeye RL. Abruptio placentae and placenta previa: frequency, perinatal mortality and cigarette smoking. Obstet Gynecol 1980;55(6):701-704. PMID: 7383456.

12. Salihu HM, Li Q, Rouse DJ, et al. Placenta previa: neonatal death after live births in the United States. Am J Obstet Gynecol 2003;188(5): 1305-1309. DOI: 10.1067/mob.2003.303.

13. Druzin ML. Packing of lower uterine segment for control of postcesarean bleeding in instances of placenta previa. Surg Gynecol Obstet 1989;169(6):543-545. PMID: 2814771.

14. Wath CA, Ananth CV, Smulian JC, et al. The Histological evidence of inflammation and risk of placental abruption. Am J Obstet Gynecol 2007;197(3):319. Available from: https://doi.org/10.1016/ j.ajog.2007.06.012.

15. Dommisse J, Tiltmam AJ. Placental bed biopsies in placental bed. BJOG 1992;99(8):651-654. Available from: https://doi. org/10.1111/j.1471-0528.1992.tb13848.x.

16. Fox H. Placenta accrete, 1945-1969. Obstet Gynecol Surv 1972; 27(7): 475-490. Available from: https://journals.Iww.com/obgynsurvey/toc/.

17. Hardardottir H, Borgida AF, Sanders MM. Histological myometrial fibers adherent to placenta: Impact of method of placenta removal. Am J Obstet Gynecol 1996;174:358.

18. Brosen I, Robertson WB, Dixon HG. The physiological response of the vessels of the placental bed to normal pregnancy. J Pathol Bacteriol 1967;93:253-266. DOI: 10.1002/path.1700930218. PMID: 6054057. Available from: https://doi.org/10.1002/path.1700930218.

19. Bieniarz J. The patho-mechanism of late pregnancy toxemia and obstetrical haemorrhage 1. Contradiction in the clinical picture of eclampsia and placenta previa depending upon the placental site. Am J Obstet Gynecol 1958;75(2):444-453. DOI: 10.1016/00029378(58)90411-3.

20. Biswas R, Sawhaey H, Dass R, et al. Histological study of placental bed biopsy in placenta praevia. Acta Obstet Gynecol Scand 1999;78(3):173-179. PMID: 10078576.

21. Zhang J, Savitz DA. Maternal age and placenta previa. A population based, case control study. Am J Obstet Gynecol 1993;168(2):641-645. DOI: 10.1016/0002-9378(93)90511-g.

22. McFadyen IR, Price AB, Geirsson RT. The relation of birth weight to histological appearance in vessels of placental bed. $\mathrm{Br} J$ Obstet Gynaecol 1986;93(5):476-481. PMID: 3707878.

23. Gerretsen G, Huisje HJ, Elema JD. Morphological changes of spiral arteries in the placental bed in relation to preeclampsia and fetal growth retardation. Br J Obstet Gynaecol 1981;88(9):876-881. DOI: 10.1111/j.1471-0528.1981.tb02222.x.

24. Meekins JW, Pijnenborg R, Hanseens M, et al. A study of placental bed spiral arteriols and tro-phoblastic invasion in normal and severe preeclamptic pregnancies. Br J Obstet Gynaecol 1994;101(8):669-675. DOI: 10.1111/j.1471-0528.1994.tb13182.x.

25. Khong TY, Robertson WB. Placenta accreta and placenta previa accreta. Placenta 1987;8(4):399-409. DOI: 10.1016/0143-4004(87)90067-1.

26. Leibermann JR, Fraser D, Kasis A, et al. Reduced frequency of hypertensive disorder in placenta previa. Obstet Gynecol 1991;77(1):83-86. PMID: 1984232.

27. Ananth CV, Bowes Jr WA, Sautz DA, et al. Relationship between pregnancy induced hypertension and placenta previa. A population based study. Am J Obstet Gynecol 1997;177(5):997-1002. DOI: 10.1016/ s0002-9378(97)70003-6.

28. Lin S, Shimizu I, Suehara N, et al. Uterine artery Doppler velocimetry in relation to trophoblastic migration into the myometrium of the placental bed. Obstet Gynecol 1995;85:760-765. DOI: 10.1016/00297844(95)00020-r. 


\section{Consolidated Standards of Reporting It is Trials (Consort) Statement}

Allocation done SNOSE, where sequence [generated computerized random number generator and envelopes size, shape, weight confirmed equally having-Code-Gr-A (cases), Code-Gr-B (controls).

Aluminum foil was used inside the envelopes to render envelops impermeable to light.

The envelops were opened sequentially only after the name and other details of the participants were written on them.

The envelops contain carbon papers which are essential for audit trial.

The patients' profiles were entered on the registry.

Enrolment

Allocation
Assessed for eligibility $(N=64)$

Excluded $(N=0)$

Not meeting inclusion criteria $(N=0)$

Declined to participate $(N=0)$

Other reasons $(N=0)$

Randomized $(N=64)$

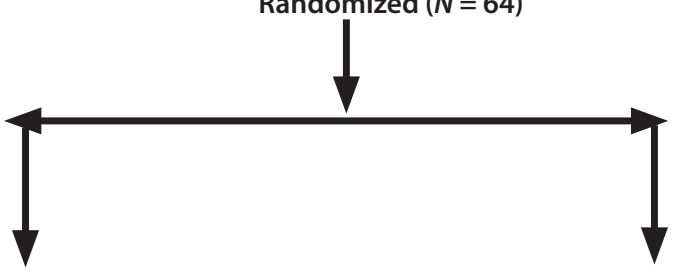

Allocated to Intervention ( $\mathrm{Gr}-\mathrm{B}-\mathrm{N}=32$ )

Received allocated intervention $(N=32)$

Did not receive allocated int. $(N=0)$

Follow-up (32)

Lost to follow-up (Reason, $N=0$ )

Discontinue intervention (Reason, $N=0$ )

Analysis

Analyzed $(N=32)$

Excluded from analysis (Reason, $N=0$ ) 